\title{
Efficacy of a single intramuscular injection of porcine FSH in hyaluronan prior to ovum pick-up in Holstein cattle
}

\section{L.M. Vieira $^{\text {a, } *}$, C.A. Rodrigues ${ }^{b}$, A. Castro Netto ${ }^{\text {c }}$, B.M. Guerreiro ${ }^{\text {a }}$, C.R.A. Silveira ${ }^{\mathrm{d}}$, B.G. Freitas ${ }^{\text {a }}$, L.G.M. Bragança ${ }^{\mathrm{e}}$, K.N.G. Marques ${ }^{\mathrm{e}}$, M.F. Sá Filho ${ }^{\mathrm{a}}$,} G.A. Bó ${ }^{\mathrm{f}}$, R.J. Mapletoft ${ }^{\mathrm{g}}$, P.S. Baruselli ${ }^{\mathrm{a}, *}$

a Departamento de Reprodução Animal, FMVZ/USP, São Paulo, SP, Brazil

${ }^{\mathrm{b}}$ Clínica Veterinária Samvet São Carlos, São Carlos, SP, Brazil

${ }^{\mathrm{c}}$ FinInVitro Reprodução Animal, Bauru, SP, Brazil

${ }^{\mathrm{d}}$ Departamento de Reprodução Animal, UNESP, Jaboticabal, SP, Brazil

${ }^{\mathrm{e}}$ NeoGen Reprodução Assistida, Tapiratiba, SP, Brazil

f Instituto de Reproducción Animal Córdoba (IRAC), Córdoba, Argentina

${ }^{\mathrm{g}}$ Department of Large Animal Clinical Sciences, Western College of Veterinary Medicine, University of Saskatchewan, Saskatoon,

Saskatchewan, Canada

\section{A R T I C L E I N F O}

\section{Article history:}

Received 4 May 2015

Received in revised form 14 October 2015

Accepted 28 October 2015

\section{Keywords:}

Bovine

Bos taurus

Follicle-stimulating hormone half-life

In vitro embryo production

Oocyte competence

\begin{abstract}
A B S T R A C T
Plasma FSH profiles, in vitro embryo production (IVP) after ovum pickup (OPU), and establishment of pregnancy with IVP embryos were compared in untreated Holstein oocyte donors and those superstimulated with multiple injections or a single intramuscular (IM) injection of porcine FSH (pFSH) in hyaluronan (HA). Plasma FSH profiles were determined in 23 heifers randomly allocated to one of four groups. Controls received no treatment, whereas the F200 group received $200 \mathrm{mg}$ of pFSH in four doses, 12 hours apart. The F200HA and F300HA groups received 200- or $300-\mathrm{mg}$ pFSH in $5 \mathrm{~mL}$ or $7.5 \mathrm{~mL}$, respectively of a $0.5 \%$ HA solution by a single IM injection. Plasma FSH levels were determined before the first pFSH treatment and every 6 hours over 96 hours. All data were analyzed by orthogonal contrasts. Circulating FSH area under curve (AUC) in pFSH-treated animals was greater than that in the control group $(P=0.02)$. Although the AUC did not differ among FSH-treated groups $(P=0.56)$, the total period with elevated plasma FSH was greater in the F200 group than in the HA groups $(\mathrm{P}<0.0001)$. However, the F300HA group had a greater AUC than the F200HA group $(P=0.006)$, with a similar total period with elevated plasma FSH $(\mathrm{P}=0.17)$. The IVP was performed in 90 nonlactating Holstein cows randomly allocated to one of the four treatment groups as in the first experiment. A greater proportion of medium-sized $(6-10 \mathrm{~mm})$ follicles was observed in cows receiving $\mathrm{pFSH}$, regardless of the treatment group $(P<0.0001)$. Also, numbers of follicles $(P=0.01)$, cumulus-oocyte complexes $(\mathrm{COCS})$ retrieved $(\mathrm{P}=0.01)$ and matured $(\mathrm{P}=0.02)$, cleavage rates $(\mathrm{P}=0.002)$, and blastocysts produced per OPU session $(\mathrm{P}=0.06)$ were greater in cows receiving pFSH, regardless of the treatment group. Cows in the F200HA group had a greater recovery rate $(P=0.009)$, number of COCs cultured $(P=0.04)$, and blastocysts produced per OPU session $(\mathrm{P}=0.06)$ than cows in the F300HA group. Similar pregnancy rates were observed 50 to 60 days after transferring IVP embryos from donors in the different treatment groups $(\mathrm{P}>0.05)$. In conclusion, a single IM injection of $\mathrm{pFSH}$ combined in $0.5 \%$ HA resulted in similar plasma FSH profiles as twice-daily pFSH treatments. Treatment of nonlactating donors with $\mathrm{pFSH}$, with or without HA, resulted in increased IVP
\end{abstract}

\footnotetext{
* Corresponding authors. Tel./fax: +55 (11) 30917674.

E-mail addresses: lavieira@usp.br (L.M. Vieira), barusell@usp.br (P.S. Baruselli).
} 
over untreated controls. A single dose of $200 \mathrm{mg}$ of pFSH in $0.5 \%$ HA resulted in greater IVP than $300-\mathrm{mg}$ pFSH in HA. Finally, pregnancy rates with IVP embryos were similar, regardless donor treatment.

(c) 2016 Elsevier Inc. All rights reserved.

\section{Introduction}

Genetic improvement has led the effort to enhance dairy cattle productivity. Among breeding alternatives, in vitro-produced embryo transfer is a robust tool used to enhance genetic progress through both the female and male lineage. However, large-scale efficient use of this reproductive strategy in dairy cattle has been a challenge. The main factors affecting the efficacy of ovum pickup (OPU) and in vitro embryo production (IVP) include: (1) reduced oocyte quality [1-4], mainly in lactating Holstein cows compared to Holstein heifers [5] and beef cattle [6]; (2) low antral follicle populations, especially in Bos taurus breeds [7]; and (3) variation between females [8,9]. Therefore, various strategies have been designed to improve the results from IVP programs with Holstein donors.

Among the strategies used, ovarian antral follicle counts in the donors, evaluated directly by ultrasonography [10-14] or indirectly by the concentrations of antiMullerian hormone [7,15-18] are beginning to be applied in the field. Another alternative is the use of follicular wave synchronization protocols associated with superstimulation treatments before the OPU [19-21]. Earlier studies reported associations between IVP outcomes and the stage of follicular growth at which OPU is performed [22-26]. During follicular and oocyte growth, the oocyte acquires its developmental potential progressively [27-32] due to the constant increase in the cytoplasmic storage of messenger RNA and proteins [33], essential for early embryo development [34]. Superstimulation treatments with porcine FSH ( $\mathrm{pFSH}$ ) before the OPU has improved IVP in Bos taurus donors, resulting in increased total embryo yields per OPU session [19-21,35], possibly due to healthier and more competent oocytes recovered from the greater proportion of medium-sized follicles.

Traditional superstimulatory treatments consist of twice-daily intramuscular (IM) injections of pFSH for in vivo [36] or in vitro $[19,37]$ embryo production. The need of frequent applications to induce ovarian superstimulation $[38,39]$ is due to the short half-life of FSH ( 5 hours) in cattle $[39,40]$. Explicitly, superstimulation protocols require precision and attention to minimize mishandling during the treatments. Therefore, the application of traditional superstimulatory protocols in large-scale programs can lead to failures and poor results, suggesting the need for simplified protocols that can be implemented efficiently and easily in the field by reducing handling and consequently, the incidence of potential errors.

Considering the need to develop a simplified superstimulation protocol, studies have focused on alternative methods to maintain FSH release during a prolonged period of time. An alternative that has been studied for in vivo embryo production is the use of a single injection of $\mathrm{pFSH}$ in a hyaluronan (HA) solution [41]. The HA is a biodegradable polymer that apparently results in a sustainable slow release of hormones. Previous studies reported a similar number of transferable embryos when a single (in $2 \% \mathrm{HA}$ ) [41] or two (in $0.5 \%$ or $1 \% \mathrm{HA}$ ) [42] IM injections of pFSH was administered compared to the traditional twice-daily IM injection protocol. The same authors emphasized that the need for the second injection is related to the concentration of HA; the lower concentrations are less viscous and easier to mix with pFSH but are not as efficacious in sustaining circulating FSH levels [41,42]. Therefore, considering the shorter period of FSH support required for superstimulation before OPU [19,43] compared to traditional multiple ovulation and in vivo embryo procedures (reviewed by Mapletoft and Bó [36]), the use of a single injection of pFSH in $0.5 \% \mathrm{HA}(5 \mathrm{mg} / \mathrm{mL})$ might be an alternative to simplify the superstimulatory protocol for OPU-IVP programs. In a preliminary study performed in beef donor cows, the administration of $160 \mathrm{mg}$ of pFSH diluted in $0.5 \%$ HA resulted in a comparable number of cumulus-oocyte complexes (COCs) recovered and blastocysts produced as the administration of $160-\mathrm{mg}$ pFSH in twice-daily IM injections [44].

Thus, the objectives of the present study were: (1) to compare plasma FSH profiles when two different doses of pFSH were combined with $0.5 \%$ HA with twice-daily injections of pFSH in saline; (2) to evaluate the FSH support needed to obtain growth of a homogeneous population of medium-sized follicles for OPU; (3) to compare OPU-IVP outcomes after superstimulation with two different doses of pFSH administrated as a single IM injection in $0.5 \% \mathrm{HA}$ with twice-daily injections of pFSH in saline, and; (4) to determine the viability of IVP embryos after superstimulation by transfer to synchronous beef heifer recipients.

\section{Materials and methods}

\subsection{Experiment 1: plasma FSH profiles}

\subsubsection{Farm and animals}

The experiment was conducted during July and August of 2014 on a state research farm (Institute of Animal Science) located in Nova Odessa, São Paulo, Brazil. The heifers enrolled in the experiment were maintained in dry-lot pens and fed with a total mixed ration formulated to meet or exceed the minimum nutritional requirements for Holstein heifers [45]. All heifers had free access to water and mineralized salt. On the first day of the trial, animals were on average of $330.0 \pm 52.9 \mathrm{Kg}( \pm$ standard deviation $)$ in weight, $13.5 \pm 2.2$ months ( \pm standard deviation) of age and a body condition score of $2.7 \pm 0.3$ (1-5 scale [46]).

\subsubsection{Experimental design}

A total of 23 Holstein heifers were randomly allocated to one of four groups (control, F200, F200HA, or F300HA 
groups). On a random day of the estrous cycle (Day 0), all heifers received a Norgestomet ear implant (Crestar; MSD Animal Health, The Netherlands), $2.0 \mathrm{mg}$ of IM estradiol benzoate (RIC-BE, Tecnopec, Brazil), and $0.150 \mathrm{mg}$ of cloprostenol (ESTRON, Tecnopec). On Day 5, all heifers received another $0.150 \mathrm{mg}$ of cloprostenol and on Day 7 were submitted to an ultrasound evaluation to obtain the diameter of the largest visible follicle present in the ovaries (average diameter of $10 \pm 0.7 \mathrm{~mm}$ ). Control heifers received no further treatments. On Days 8 and 9, the F200 group received a total dosage of $200 \mathrm{mg}$ of $\mathrm{pFSH}(14.3 \mathrm{mg} / \mathrm{mL}$ in saline diluent; Folltropin, Bioniche Animal Health, Belleville, ON, Canada) administered intramuscularly in four doses (57.1, 57.1, 42.9 and $42.9 \mathrm{mg}), 12$ hours apart. The HAtreated heifers received a single dose of pFSH (IM) on Day 8 AM (ante meridiem or before midday) in $5.0 \mathrm{~mL}$ (F200HA) or $7.5 \mathrm{~mL}$ (F300HA) of $0.5 \%$ hyaluronan ( $40 \mathrm{mg} / \mathrm{mL}$ of $\mathrm{FSH}$; MAP-5, Bioniche Animal Health). On Day 12 AM, the Norgestomet ear implant was removed after the last blood sample (Fig. 1).

The methodology used to suppress endogenous FSH release was based on reproductive physiology and knowledge of endocrinology. The synchronization of follicular wave emergence permitted the initiation of FSH treatments 4 days after follicular wave emergence, when a growing dominant follicle should have been selected and when endogenous FSH concentrations should be at baseline (reviewed by Baruselli, Sá Filho [4]). As reviewed by Mapletoft, Bó [47], endogenous FSH is suppressed by estradiol and inhibin, hormones produced by the growing follicles, and especially the dominant follicle. Additionally, two doses of cloprostenol were administered to ensure low progesterone levels and, thus, support the dominant follicle growth. Lastly, recommended doses of Norgestomet ear implant are associated with greater $\mathrm{LH}$ support of the development of the dominant follicle [48].

\subsubsection{Blood sample collection and plasma FSH quantification}

Starting on Day 8 (immediately before the first pFSH treatment), blood samples were collected from the jugular vein at $0,6,12,18,24,30,36,42,48,54,60,66,72,78,84,90$, and 96 hours $(\mathrm{n}=23)$ for plasma pFSH concentrations. Approximately, $8 \mathrm{~mL}$ was collected into heparinized tubes and immediately placed in ice. Plasma was separated by centrifugation $(2000 \times \mathrm{g}$ for 15 minutes at room temperature) and stored at $-20{ }^{\circ} \mathrm{C}$ until assayed. Quantification of FSH was performed by radioimmunoassay validated for bovine FSH using USDA-bFSH for iodination and reference standards, and NIDDK-anti-oFSH antiserum [49]. Two assays were performed on each sample; sensitivity was $0.03 \mathrm{ng} / \mathrm{mL}$ and intra- and inter-assay coefficients of variation were $20.3 \%$ and $10.5 \%$ for high concentrations and $9.2 \%$ and $18.4 \%$ for low concentrations. The analyses were performed in the Laboratory of Animal Endocrinology at the University of the State of São Paulo (UNESP), Araçatuba, São Paulo, Brazil.

\subsection{Experiment 2: in vitro embryo production followed ovum pickup (OPU-IVP) and pregnancy establishment after transferring in vitro-produced embryos}

\subsubsection{Farm and animals}

This experiment was conducted on two commercial dairy farms in Southeast Brazil $\left(22^{\circ} 01^{\prime} 27^{\prime \prime} \mathrm{S} / 47^{\circ} 53^{\prime} 19^{\prime \prime} \mathrm{W}\right)$ during October of 2013 and February of 2014. The herds were composed of approximately 1500 lactating Holstein cows housed in free stall facilities, milked three times daily and with an average milk production of $30.1 \pm 0.3 \mathrm{~kg}$ per day.

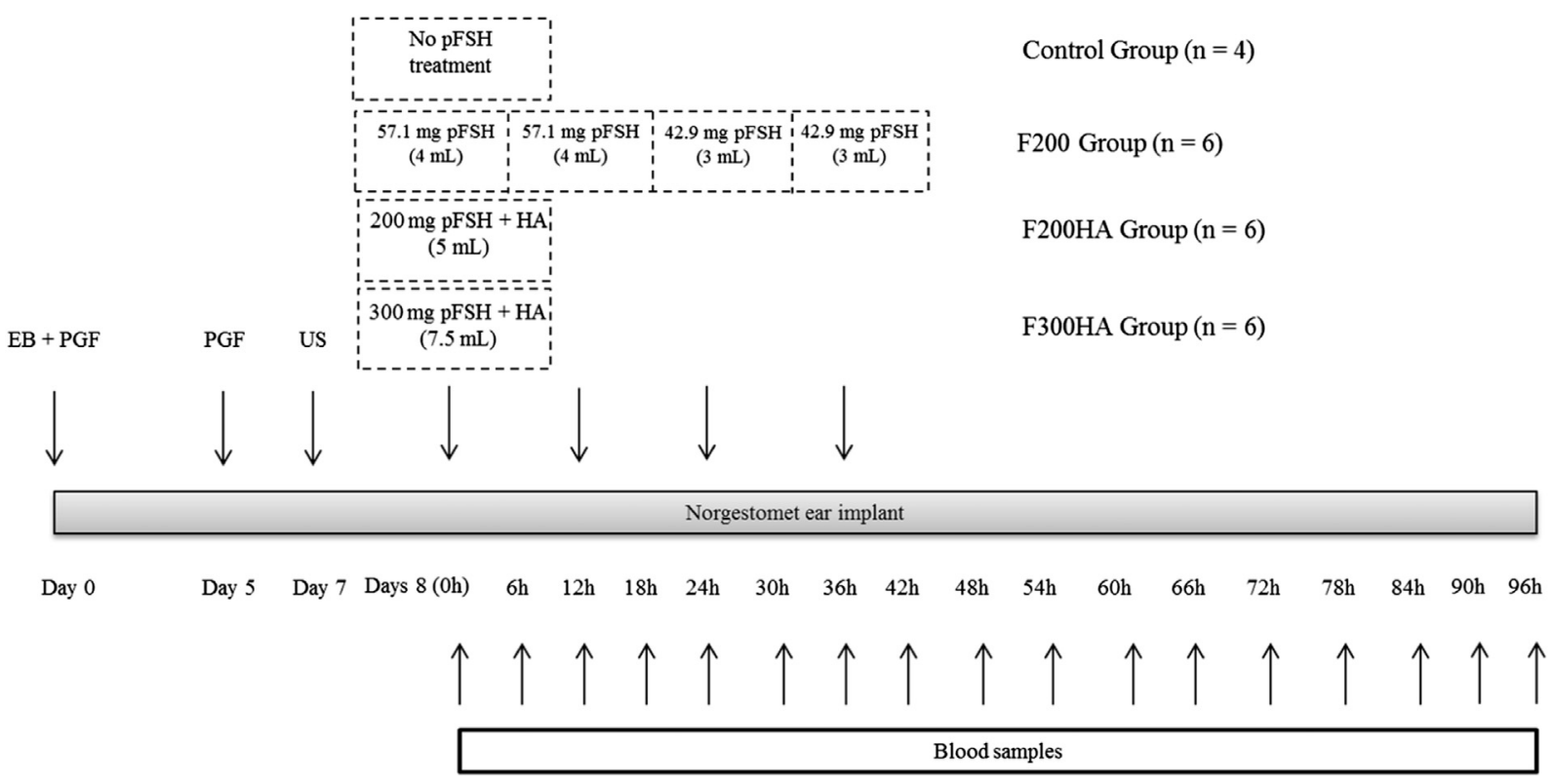

Fig. 1. Experiment 1 design: Heifers were assigned to one of four groups to compare plasma FSH profiles. Holstein heifers were not treated (control, $\mathrm{n}=4$ ), treated with $200 \mathrm{mg}$ of pFSH divided into twice-daily injections (F200, $\mathrm{n}=6$ ) or 200 or $300 \mathrm{mg}$ of pFSH in $0.5 \%$ hyaluronan as a single injection (F200HA, $\mathrm{n}=6$ and F300HA, $n=6$ ). EB, $2.0 \mathrm{mg}$ of estradiol benzoate; PGF, $0.150 \mathrm{mg}$ of cloprostenol; US, ultrasound evaluation to obtain the largest follicle diameter; pFSH, porcine follicle-stimulating hormone; HA, Hyaluronan. 
The donors were nonlactating Holstein cows selected by genetic merit, 5 years of age with two to three previous lactations, maintained in dry-lot pens and fed a total mixed ration formulated to meet the minimum nutritional requirements for nonlactating Holstein cows [45]. Briefly, the main ingredients were corn silage and Tifton hay as forage, and corn, soybean and cottonseed meal-based concentrate. The embryo recipients were crossbred (Bos indicus $\times$ Bos taurus) beef heifers maintained on Brachiaria decumbens pastures. All animals had free access to water and mineralized salt.

\subsubsection{Experimental design}

A total of 90 nonlactating Holstein donors were enrolled at random in one of the four groups: control $(\mathrm{n}=22)$; F200 ( $\mathrm{n}=23)$; F200HA $(\mathrm{n}=22)$; and F300HA $(n=23)$. On random days of the estrous cycle (Day 0$)$, all cows received an intravaginal progesterone device (P4; Primer, Tecnopec) and $2.0 \mathrm{mg}$ of IM estradiol benzoate (BE, RIC-BE, Tecnopec). The control group received no superstimulatory treatment. On Days 4 and 5, the F200 group received total dosage of $200 \mathrm{mg}$ of $\mathrm{pFSH}$ (Folltropin) in saline divided in four doses (57.1, 57.1, 42.9, and $42.9 \mathrm{mg}$ ), administered 12 hours apart. The groups containing pFSH in hyaluronan (40 mg/mL; MAP-5) received a single dose (IM) on Day 4 AM, $5.0 \mathrm{~mL}$ (F200HA), and $7.5 \mathrm{~mL}$ (F300HA). Immediately before OPU (Day 7 AM), the P4 devices were withdrawn (Fig. 2).

\subsubsection{Ultrasonography examinations}

Immediately before the OPU session, both ovaries were examined by transrectal ultrasonography using a portable scanner (Aloka SSDV 500; Aloka, Tokyo, Japan) with 5-MHz convex array transducer housed in a plastic vaginal guidance device. All follicles suitable to be punctured (diameter $\geq 2 \mathrm{~mm}$ ) were quantified and classified according to their diameters (small [SF $<6 \mathrm{~mm}$ ], medium $[\mathrm{MF}=6-10 \mathrm{~mm}]$, and large $[\mathrm{LF} \geq 10 \mathrm{~mm}$ ] follicles).

\subsubsection{Ovum pickup}

For the COC collection, cows were restrained in a chute and epidural anesthesia was administered with $2 \%$ lidocaine hydrochloride (Lidovet, Bravet, Brazil) to facilitate the handling of the ovaries through the rectum. The perineal area was cleaned using water, dried, and sprayed with $70 \%$ alcohol before each session. All follicles greater than or equal to $2 \mathrm{~mm}$ were aspirated using the portable scanner with a 5-MHz convex array transducer housed in a plastic vaginal guidance device with a stainless steel needle guide connected to aspiration equipment and a vacuum system. Follicular aspirates were recovered via a $1.1 \mathrm{~mm}$ internal diameter by a $120-\mathrm{cm}$ length circuit (Watanabe Tecnologia Aplicada, Cravinhos, SP, Brazil), connected directly to a disposable 18-gauge $\times 2$ inch hypodermic needle $(0.9 \times 50 \mathrm{~mm}$; Terumo Europe NV-Belgium) and a $50-\mathrm{mL}$ conical tube containing $15 \mathrm{~mL}$ of Dulbecco PBS (DPBS; Nutricell Nutrientes Celulares, Campinas, SP, Brazil) supplemented with $1 \%(\mathrm{v}: \mathrm{v})$ fetal calf serum (FCS; Gibco Life Technologies, Grand Island, NY) and $5000 \mathrm{IU} / \mathrm{mL}$ sodium heparin (Parinex, Hipolabor, Belo Horizonte, MG, Brazil) at $35^{\circ} \mathrm{C}$ to $37^{\circ} \mathrm{C}$. The vacuum connected to the needle was set at $100 \mathrm{mmHg}$. To avoid reduced recovery rate in superstimulated donors [19], a greater needle diameter (18-ga) and vacuum pressure $(100 \mathrm{mmHg})$ were used based on Bols, Van Soom [50]. All retrieval procedures were performed by two veterinarians. The conical tube containing the follicular aspirate was transported to a field laboratory, and COCs were recovered using a 75- $\mu \mathrm{m}$ filter (Watanabe Tecnologia Aplicada) and DPBS supplemented with 1\% FCS. The COCs were washed once in DPBS supplemented with $1 \% \mathrm{FCS}$ at $37^{\circ} \mathrm{C}$ and evaluated under a stereomicroscope at magnification $\times 8$ to $\times 20$. The COCs were morphologically

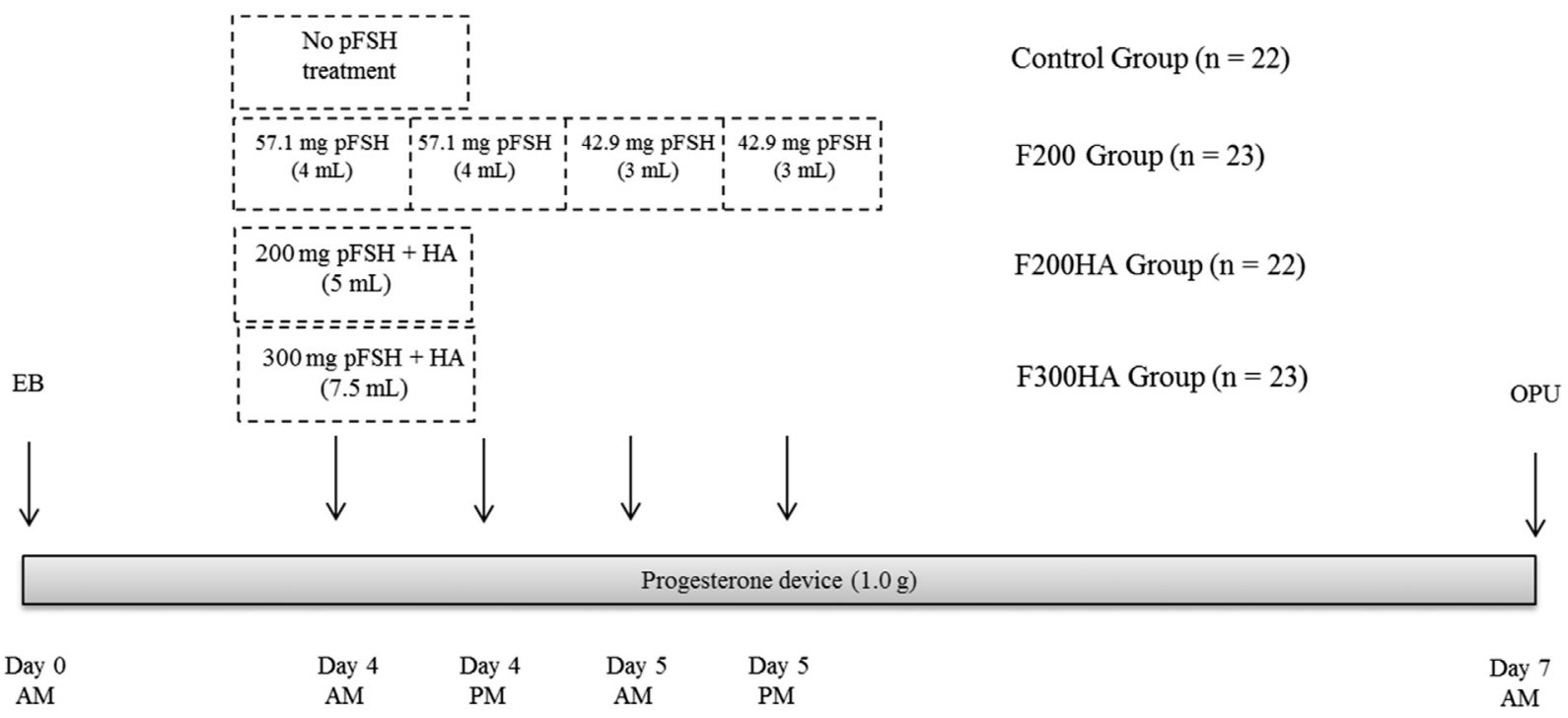

Fig. 2. Experiment 2 design: Nonlactating Holstein cows were allocated to one of four groups for in vitro embryo production after OPU. Cows were not treated (control, $\mathrm{n}=22$ ), treated with $200 \mathrm{mg}$ of pFSH (F200, $\mathrm{n}=23$ ) in twice-daily injections or 200 or $300 \mathrm{mg}$ of pFSH combined with $0.5 \%$ hyaluronan solution (F200HA, $\mathrm{n}=22$ and F300HA, $\mathrm{n}=23$ ) as a single intramuscular injection. EB, $2.0 \mathrm{mg}$ of estradiol benzoate; pFSH, porcine follicle-stimulating hormone; HA, 0.5\% hyaluronan; OPU, ovum pickup. 
classified based on the number of cumulus cell layers as follows: grade 1, more than three layers of compact cumulus cells; grade 2, at least one layer of cumulus cells; grade 3, denuded; and grade 4, atretic, with dark cumulus cells and signs of cytoplasmic degeneration [51]. After evaluation, only grade 4 COCs were considered unsuitable and discarded. The remaining COCs were considered suitable for culture, maintained in maturation medium, and transported to the commercial IVP laboratory (Bioembryo Biotecnologia da Reprodução Animal, Bauru, SP or Neogen Reprodução Assistida, Tabiratiba, SP) at $37^{\circ} \mathrm{C}$ to $39^{\circ} \mathrm{C}$.

\subsubsection{In vitro embryo production}

The in vitro maturation (IVM) medium was composed of bicarbonate-buffered TCM-199 (Gibco Life Technologies) supplemented with $10 \%$ FCS, $50 \mu \mathrm{g} / \mathrm{mL}$ of LH (APL, Ayerst, Rouses Point, NY), $5 \mu \mathrm{g} / \mathrm{mL}$ of pFSH (Folltropin-V), $0.1 \mu \mathrm{g} / \mathrm{mL}$ of estradiol (Estradiol 17 $\beta$; Sigma-Aldrich Chemical Co.), $22 \mu \mathrm{g} / \mathrm{mL}$ of sodium pyruvate, and $50 \mu \mathrm{g} / \mathrm{mL}$ of gentamycin. The COCs of each cow were cultured separately for 24 hours (considering the transport period to the lab) in $100-\mu \mathrm{L}$ drops of maturation medium under mineral oil (D'Altomare, São Paulo, SP, Brazil) at $39{ }^{\circ} \mathrm{C}$ in an atmosphere of $5 \% \mathrm{CO}_{2}$ in humidified air. After 24 hours of IVM, the COCs were washed and subjected to IVF in 100- $\mu$ L drops of IVF medium under mineral oil. The IVF medium was Tyrode's albumin lactate pyruvate supplemented with $10 \mu \mathrm{g} / \mathrm{mL}$ of heparin, $22 \mu \mathrm{g} / \mathrm{mL}$ of sodium pyruvate, $50 \mu \mathrm{g} / \mathrm{mL}$ of gentamycin, $6 \mathrm{mg} / \mathrm{mL}$ of fatty acid-free BSA, and PHE solution $(2-\mu \mathrm{M}$ penicillin, $1-\mu \mathrm{M}$ hypotaurine, and 0.25- $\mu \mathrm{M}$ epinephrine; [52]).

For IVF, semen straws of three sires, homogeneously distributed among experimental groups, were thawed for 30 seconds in a $35^{\circ} \mathrm{C}$ water bath and semen was deposited on a $90 \%$ to $45 \%$ Percoll gradient prepared with sperm wash medium (modified Tyrode medium) and centrifuged at $320 \times \mathrm{g}$ for 30 minutes to separate the motile sperm and to remove the diluents and seminal plasma. Then, the sperm pellet was evaluated for concentration and motility by the addition of IVF medium. Each fertilization droplet received $5 \mu \mathrm{L}$ of sperm, to achieve a final concentration of $1 \times 10^{6}$ live sperm $/ \mathrm{mL}$. Sperm and COCs were incubated at $38.5^{\circ} \mathrm{C}$ in an atmosphere of $5 \% \mathrm{CO}_{2}$ in humidified air for 18 to 20 hours (starting 24 hours after OPU procedure).

Approximately 18 hours after IVF, presumptive zygotes were stripped of cumulus cells by mechanical pipetting in Tyrode's albumin lactate pyruvate medium. Groups of presumptive zygotes were cocultured on a monolayer of cumulus cells that had attached to the surface of the plate during IVM. Thus, to maintain the maximum amount of cumulus cells, the IVM medium was gently replaced with CR2aa medium [53] supplemented with 2\% FCS and $30 \mathrm{mg} / \mathrm{mL}$ of BSA for embryo culture in $100-\mu \mathrm{L}$ drops at $39^{\circ} \mathrm{C}$ in an atmosphere of $5 \% \mathrm{CO}_{2}$ in humidified air for 48 to 72 hours. During the first (Day 3 of culture) and second feeding (Day 5 of culture), half of the drop volume (50 $\mu \mathrm{L})$ was replaced by fresh medium during all embryo culture procedures. Cleavage rate was recorded after 3 days of embryo culture (number of cleaved zygotes divided by number of cultured COCs) and blastocyst rate after 7 days of embryo culture (number of blastocysts divided by number of cultured COCs).

\subsubsection{Embryo transfer and pregnancy diagnosis}

A subset of the fresh in vitro-produced embryos (control: $\mathrm{n}=18$, F200: $\mathrm{n}=23$, F200HA: $\mathrm{n}=11$, and F300HA: $\mathrm{n}=20$ ) were transferred nonsurgically into the uterine horn ipsilateral to the $\mathrm{CL}$ of recipients on the basis of detection of estrus synchronous with the stage of development of the embryos, as previously described in detail by Rodrigues et al. [54]. On the day of embryo transfer, recipients were assessed by transrectal palpation for the presence of CL. Pregnancy diagnosis was performed by transrectal palpation 50 to 60 days after embryo transfer. The detection of asymmetry of the uterine horns and amniotic vesicle was used as an indicator of pregnancy.

\subsection{Statistical analysis}

Statistical analyses were performed using Statistical Analysis System for Windows (SAS 9.3). In experiment 1, area under the curve (AUC) of plasma FSH was calculated by the trapezoid method. Total period with elevated plasma FSH concentration was determined as the time interval from the onset of the increase of FSH (baseline concentration before the increase in FSH concentration induced by the first pFSH treatment) to its last return to baseline concentrations after the last pFSH treatment. The increase in FSH was defined as twice the standard deviation above the overall within-cow mean of FSH concentrations. In the control group, one heifer had an increased FSH concentration at 72 hours; therefore, it was excluded from the analysis. In experiment 2, the variables evaluated were number of follicles suitable to be punctured in each size category at the time of OPU (small, medium, and large), number of follicles suitable to be punctured, number of COCs recovered, recovery rate (number of COCs recovered per number of follicles suitable to be punctured), number and percentage of cultured COCs (number of COCs cultured per structures recovered), cleavage rate (number of cleaved zygotes per number of COCs cultured), blastocyst rate (number of blastocysts produced per number of COCs cultured), number of embryos produced per OPU procedure and pregnancy rate after embryo transfer.

For the analysis, a binomial distribution was assumed for the categorical response variables. Continuous data were tested for normality of the residues and homogeneity of variances using the Guided Data Analysis and transformed when necessary. The fixed effect included in the model was treatment. The OPU session effect was included as a random effect. The data were analyzed by orthogonal contrasts. The contrasts established were $\mathrm{C} 1$ (superstimulation effect): control versus (F200 + F200HA + F300HA); C2 (HA effect): F200 versus (F200HA + F300HA); and C3 (dose effect): F200HA versus F300HA. Means ( \pm standard error) or percentages were used to describe the response variables.

\section{Results}

\subsection{Experiment 1: plasma FSH profiles}

The plasma FSH concentration profiles differed among treatment groups (Fig. 3). Heifers receiving pFSH treatment had greater $(\mathrm{P}=0.002 ; \mathrm{C} 1)$ AUC of plasma FSH; however, 
although F200 group was not different from HA groups $(\mathrm{P}=0.56 ; \mathrm{C} 2)$, the $\mathrm{F} 300 \mathrm{HA}$ group had greater AUC compared to the F200HA group ( $P=0.006$, Fig. 3 ; C3). Heifers receiving the F200 treatment had an extended period of greater plasma concentration of FSH compared to the groups that received a single dose of $\mathrm{pFSH}$ in $\mathrm{HA}$ $(\mathrm{P}<0.0001 ; \mathrm{C} 2)$, whereas both HA groups were similar $(\mathrm{P}=0.17$, C3; Fig. 4).

3.2. Experiment 2: ovum pickup, in vitro embryo production, and establishment of pregnancy

The numbers of follicles suitable for puncture and oocytes retrieved were greater in superstimulated groups $(P=0.01$ and $P=0.01, C 1$, respectively) but were similar among groups that received four doses of pFSH or a single dose of $\mathrm{pFSH}$ in $\mathrm{HA}(\mathrm{P}=0.97$ and $\mathrm{P}=0.78, \mathrm{C} 2$, respectively; Table 1). The number of COCs retrieved in the F300HA group tended to be lower than that in the F200HA group $(\mathrm{P}=0.09, \mathrm{C} 3$; Table 1$)$. In addition, pFSH-treated donors had a lower proportion of small follicles $(P<0.001, C 1)$ and a higher proportion of medium follicles $(P<0.001, C 1)$ at the time of OPU than the control group (Fig. 5). Cows that received four doses of $\mathrm{pFSH}$ had a greater proportion of small follicles compared to the cows that received a single dose of pFSH in HA (C2; P $=0.08$, Fig. 5). Proportions of medium $(P=0.32)$ and large follicles $(P=0.42 ; C 2)$ did not differ between cows that received four doses of $\mathrm{pFSH}$ or a single dose of pFSH in HA (Fig. 5).

Additionally, the F300HA group had a greater proportion of large follicles compared to the F200HA group $(P=0.05, C 3)$. Lastly, no difference was observed in the recovery rate between cows in the control group and superstimulated donors ( $P=0.80, C 1)$, and no difference was observed in the recovery rate between F200 and the F200HA and F300HA groups ( $P=0.67, C 2)$. However, cows in the $\mathrm{F} 300 \mathrm{HA}$ group had a lower recovery rate $(\mathrm{P}=0.009$, C3) than those in the F200HA group.

A greater number of COCs were considered suitable for culture in pFSH-treated donors $(\mathrm{P}=0.02, \mathrm{C} 1)$ than in the control group, but there was no difference among pFSH

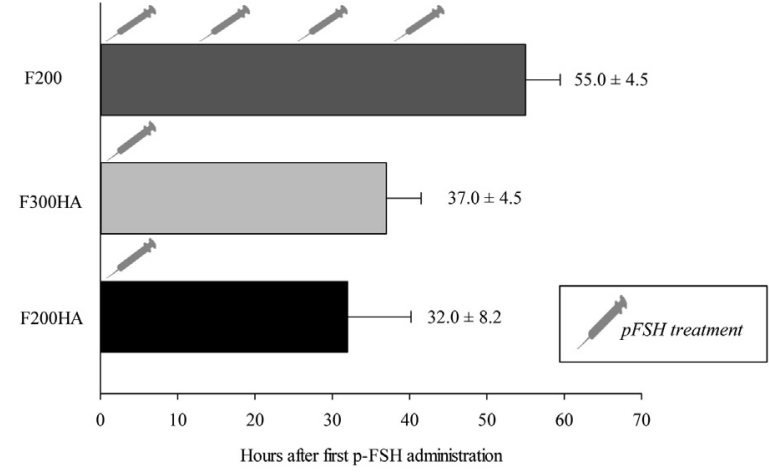

Fig. 4. Total period (in hours) that plasma FSH concentrations were elevated in Holstein heifers treated with four doses of pFSH (F200) 12 hours apart or two different doses (200 and $300 \mathrm{mg}$ ) of pFSH as a single injection in $0.5 \%$ hyaluronan (HA; F200HA and F300HA). The total period with elevated plasma FSH concentration was determined as the time interval from the onset of the FSH increase (baseline concentration before the increase in FSH concentration induced by treatment) to its return to baseline concentrations after the last pFSH treatment. Data are presented as mean \pm standard error of the mean. For the duration of pFSH treatment, the orthogonal contrasts were used: C1 (HA effect): F200 $\times($ F200HA + F300HA), P $<0.0001$ and C2 (dose effect): $\mathrm{F} 200 \mathrm{HA} \times \mathrm{F} 300 \mathrm{HA}, \mathrm{P}=0.17$.

treatment groups $(\mathrm{P}=0.56, \mathrm{C} 2)$. Within single injection with HA groups, the number of COCs suitable to culture was lower in the F300HA group than in the F200HA group $(\mathrm{P}=0.04, \mathrm{C} 3$; Table 1). Similar $(\mathrm{C} 1: \mathrm{P}=0.34, \mathrm{C} 2: \mathrm{P}=0.46$ and $\mathrm{C} 3$ : $\mathrm{P}=0.30$ ) percentages of COCs were considered suitable to use in IVP among pFSH-treated groups (Table 1).

A greater cleavage rate $(P=0.002, C 1)$ was obtained in COCs collected from donors treated with $\mathrm{pFSH}$, regardless of treatment group and those from cows in the control group (Table 1), and there was no effect of pFSH treatment group on cleavage rate $(C 2: P=0.99$ and $C 3$ : $P=0.97)$. Although there was no difference in blastocyst production rate among groups $(\mathrm{P}=0.42, \mathrm{C} 1 ; \mathrm{P}=0.80, \mathrm{C} 2$; and $\mathrm{P}=0.16$, C3), superstimulated donors produced more embryos per OPU session ( $P=0.06, C 1)$ than the control group. Among the superstimulated cows, there was no difference between twice-daily injection and single injection groups $(P=0.61$,
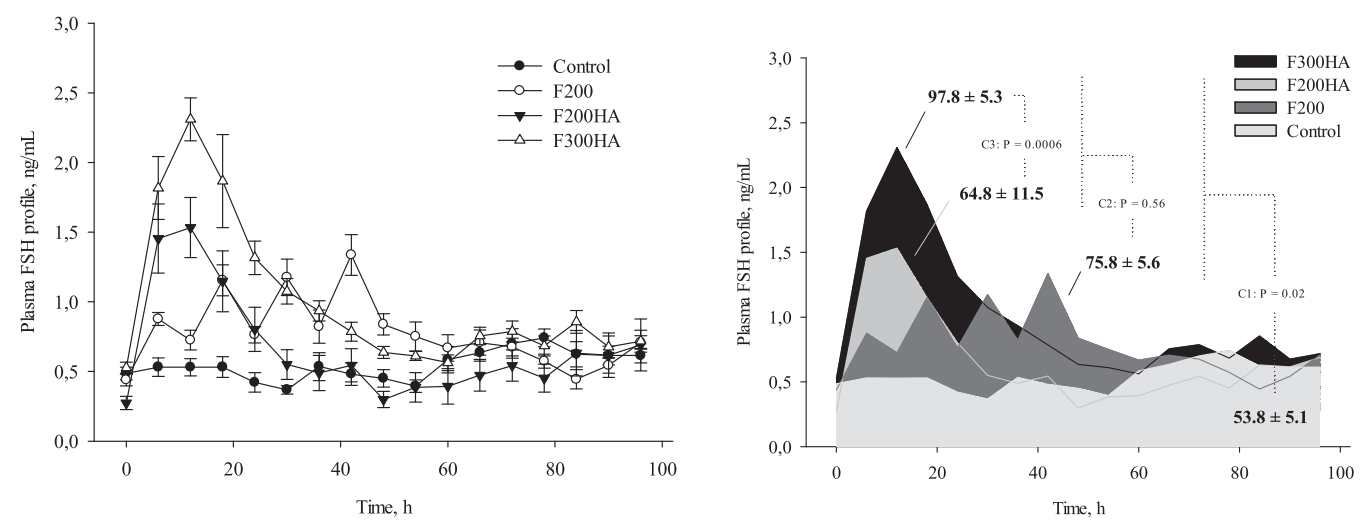

Fig. 3. Mean \pm standard error of the mean (left graph) and area under curve (AUC, ng*h/mL; right graph) in Holstein heifers following no superstimulation treatment (control) or treatment with pFSH in twice-daily injections (F200) or combined with 0.5\% hyaluronan as a single intramuscular injection (F200HA and F300HA). Circulating FSH concentrations were determined by radioimmunoassay (RIA) at 6-hour intervals for 96 hours after the first treatment. For statistical analysis, orthogonal contrasts were applied: C1 (FSH effect): control $\times($ F200 + F200HA + F300HA), P = 0.02; C2 (HA effect): F200 × (F200HA + F300HA), $\mathrm{P}=0.56$; and $\mathrm{C} 3$ (dose effect): $\mathrm{F} 200 \mathrm{HA} \times \mathrm{F} 300 \mathrm{HA}), \mathrm{P}=0.0006$. 
Table 1

Summary of cumulus-oocyte complex yield and in vitro embryo production (mean \pm standard error or percentage) in nonlactating Holstein cows that were not treated (control), treated with $200 \mathrm{mg}$ of porcine FSH (pFSH; F200) in twice-daily injections or 200 or $300 \mathrm{mg}$ of pFSH as a single injection in $0.5 \%$ hyaluronan (F200HA and F300HA).

\begin{tabular}{|c|c|c|c|c|c|c|c|}
\hline \multirow[t]{2}{*}{ Items } & \multicolumn{4}{|l|}{ Treatments } & \multicolumn{3}{|c|}{ P value } \\
\hline & Control & F200 & F200HA & F300HA & $\mathrm{C} 1$ & $\mathrm{C} 2$ & $\mathrm{C} 3$ \\
\hline No. of cows & 22 & 23 & 22 & 23 & . & . & . \\
\hline Follicles suitable for OPU & $16.1 \pm 1.1$ & $20.4 \pm 1.4$ & $23.2 \pm 2.3$ & $19.6 \pm 1.6$ & 0.01 & 0.97 & 0.24 \\
\hline COCs retrieved & $13.1 \pm 1.0$ & $16.5 \pm 1.2$ & $19.5 \pm 2.1$ & $15.4 \pm 1.4$ & 0.01 & 0.78 & 0.09 \\
\hline Recovery rate, \% & $80.8(287 / 355)$ & $81.0(379 / 468)$ & $84.0(429 / 511)$ & $78.7(355 / 451)$ & 0.80 & 0.67 & 0.009 \\
\hline COCs cultured & $9.3 \pm 0.7$ & $12.2 \pm 1.2$ & $15.6 \pm 1.7$ & $11.4 \pm 1.2$ & 0.02 & 0.56 & 0.04 \\
\hline COCs culture rate, $\%$ & $71.4(205 / 287)$ & $74.1(281 / 379)$ & $80.0(343 / 429)$ & $74.1(263 / 355)$ & 0.34 & 0.46 & 0.30 \\
\hline Cleavage rate, $\%^{\mathrm{c}}$ & $75.6(155 / 205)$ & $85.1(239 / 281)$ & $79.6(273 / 343)$ & $79.4(210 / 263)$ & 0.002 & 0.99 & 0.97 \\
\hline Blastocyst rate, \% ${ }^{\mathrm{d}}$ & $25.9(53 / 205)$ & $30.3(83 / 281)$ & $30.3(104 / 343)$ & $27.0(71 / 263)$ & 0.42 & 0.80 & 0.16 \\
\hline Embryos produced per OPU & $2.4 \pm 0.5$ & $3.7 \pm 0.7$ & $4.7 \pm 0.7$ & $3.1 \pm 0.6$ & 0.06 & 0.61 & 0.06 \\
\hline Pregnancy per ET, \% & $33.3(6 / 18)$ & $39.1(9 / 23)$ & $54.6(6 / 11)$ & $60.0(12 / 20)$ & 0.42 & 0.82 & 0.82 \\
\hline
\end{tabular}

Abbreviations: COCs, cumulus-oocyte complexes; ET, embryo transfer; OPU, ovum pickup.

a No. of COCs/no. of follicles suitable to be punctured.

b No. of COCs cultured/no. of total COCs retrieved.

c No. of cleaved zygotes/no. of COCs cultured.

d No. of blastocysts/no. of COCs cultured.

e Orthogonal contrasts: C1 (FSH effect): control $\times($ F200 + F200HA + F300HA); C2 (HA effect): F200 × (F200HA + F300HA); and C3 (dose effect): F200HA × F300HA).

C2), but the number of blastocysts produced per OPU session was lower in the F300HA than in the F200HA group $(\mathrm{P}=0.06, \mathrm{C} 3$; Table 1$)$. Finally, similar pregnancy rates were observed among groups after transferring the subset of the fresh in vitro-produced embryos $(\mathrm{C} 1: \mathrm{P}=0.42, \mathrm{C} 2: \mathrm{P}=0.82$ and $\mathrm{C} 3$ : $\mathrm{P}=0.82$; Table 1 ).

\section{Discussion}

The present study confirmed that pFSH treatment results in greater plasma FSH concentrations compared to the non-pFSH-treated controls. In particular, the

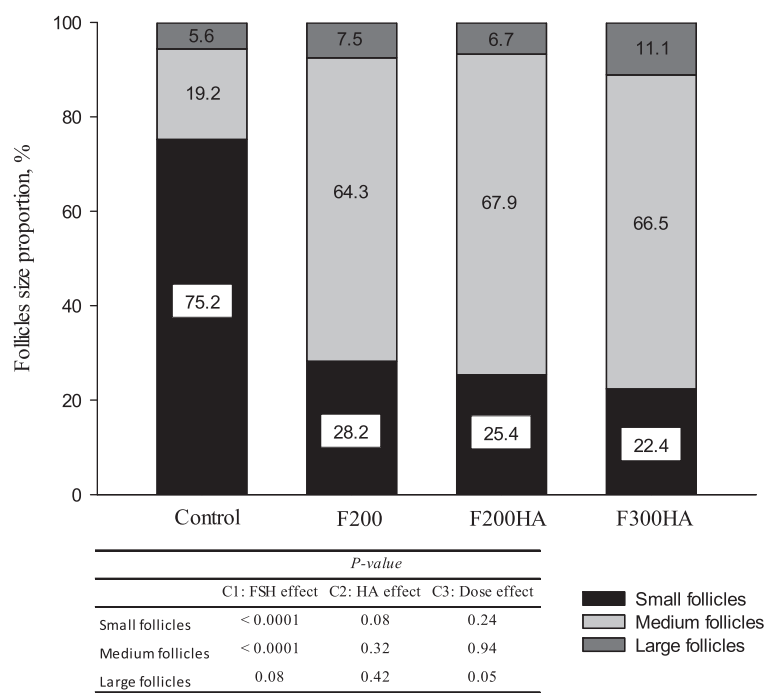

Fig. 5. Proportion of small $(<6 \mathrm{~mm})$, medium $(6-10 \mathrm{~mm})$, and large $(>10 \mathrm{~mm}$ ) follicles suitable to be punctured immediately before ovum pickup (OPU; Day 7 ) in nonlactating cows $(\mathrm{n}=90)$ submitted to OPU without previous superstimulation treatment (control), after treatment with pFSH (F200) or pFSH in hyaluronan (F200HA and F300HA). Orthogonal contrasts: C1 (FSH effect): control $\times($ F200 + F200HA + F300HA); C2 (HA effect): F200 × (F200HA + F300HA); and C3 (dose effect): F200HA $\times$ F300HA. administration of a single dose of pFSH in HA provided comparable plasma FSH concentrations (as measured by AUC) to the twice-daily pFSH treatment. The maintenance of elevated plasma FSH concentrations differed among treatment groups; FSH concentration in HA groups reached baseline in approximately 32 to 37 hours after treatment which was before the twice-daily pFSH treatment over 2 days. Moreover, in experiment 2, pFSH treatment of cows (with or without HA) increased the efficiency of OPU-IVP compared to the untreated control donors. Although plasma FSH concentrations in HA groups reached baseline before the traditional twice-daily treatment, FSH support seemed to have resulted in similar overall superstimulation and efficiency of the OPU-IVP technology, suggesting plasma FSH concentration does not need to be elevated for more than 36 hours to superstimulate donors for OPU-IVP.

Additionally, it is important to highlight that the higher dose of pFSH in HA (300 mg) resulted in greater proportion of large follicles, but reduced $\mathrm{COC}$ recovery rate and the number of embryos produced per OPU session compared to the group that received only $200 \mathrm{mg}$ of $\mathrm{pFSH}$ combined with HA. Regardless, these data reinforce the benefits of the superstimulation treatment in the Holstein breed to enhance the IVP production and that only one injection of 200-mg pFSH diluted in 0.5\% HA is required, reducing animal handling and the potential noncompliance during the hormonal protocol.

The traditional superstimulatory protocol uses saline as a diluent, and due to the short half-life of the FSH $[39,40]$, twice-daily IM injections are required for in vivo [36] or in vitro [19,37] embryo production. On the basis of the rapid clearance of FSH ( $\sim 5$ hours) [39], regardless of the dose administered [55], an alternative could be to modify hormone absorption. Modifications examined have included changing the route administration (subcutaneous injection, [55-57]) or mixing the pFSH with polymers, such as polyvinylpyrrolidone [58], aluminum hydroxide gel [59] or HA [42] to reduce the rate of absorption. Tríbulo et al. [42] reported satisfactory superovulatory results after treating 
donors with a single dose of pFSH combined with $2 \% \mathrm{HA}$. However, $2 \%$ HA was viscous and difficult to mix with $\mathrm{pFSH}$, especially in the field. A $0.5 \%$ solution of HA was much less viscous and easy to work with and resulted in a similar number of transferable embryos as twice-daily treatments when divided into two administration 48 hours apart. Although a two injection protocol seemed to be required to superovulate donor cows for in vivo embryo production, the results of the present study support the notion that only one injection of pFSH diluted in $0.5 \% \mathrm{HA}$ is required for in vitro embryo production after OPU in nonlactating Holstein donors. These results are also in agreement with those obtained after a single injection of pFSH diluted in $0.5 \% \mathrm{HA}$ in beef cows [44]. The present data verify a shortened but extended period of elevated plasma concentrations of FSH in HA groups. The extended period of elevated plasma FSH in females treated with the traditional twice-daily treatment protocol is no doubt related to the continued administration of $\mathrm{pFSH}$.

As previously reported $[19,60,61]$ and reinforced in the present study, treatment with $\mathrm{pFSH}$ increases the proportion of medium-sized follicles for OPU. The reason for increasing the proportion of medium-sized follicles for OPU has been based on the observation that oocyte developmental competence was influenced by the stage of follicular development [27-29,31]. During follicle growth, several morphologic, molecular, metabolic, and epigenetic changes occur in the COCs [62]. These changes, including molecular and transcriptional alterations, have been correlated with final oocyte development competence $[31,33,63,64]$. In addition, others have shown positive differential gene expression (genes related to transcription and cell cycle regulations [65]) of COCs retrieved from superstimulated donors compared to untreated females. However, negative differential gene expression (genes related to matrix remodeling, disturbance of angiogenesis, apoptosis, and oxidative stress response [66]) has also been reported in COCs retrieved from superstimulated donors. Although the present study did not reveal differences in pregnancy rates after transfer of the in vitro-produced embryos, additional trials are required to clarify and confirm the beneficial effects of superstimulation treatment on the overall outcomes.

Although oocyte quality has been shown to improve with follicle growth [24], follicle size has been reported to adversely affect COC recovery rate in Bos taurus cows [19,51] and heifers [20]. Seneda et al. [51] suggested that the increased volume and viscosity of follicular fluid and the greater intrafollicular pressure of larger follicles after superstimulation may hamper COC recovery. In the present study, similar recovery rates were observed among superstimulated and control groups. However, it is important to note that a greater needle diameter (18-ga) and vacuum pressure $(100 \mathrm{mmHg}$ ) were used in the present trial, which may have resulted in a greater recovery rate. In another earlier study, a greater recovery rate was observed when OPU was performed with larger needles but with a similar vacuum pressure [50]. Therefore, more detailed studies are necessary to establish an ideal approach to retrieve the maximum proportion of COCs with optimal development potential and without adverse effects after superstimulation of donors for OPU.

The oocyte development potential can be evaluated by the capacity of the $\mathrm{COC}$ to become a viable blastocyst within an IVP system [9]. Although the present study reports similar blastocyst rates among treatment groups, donors treated with pFSH, regardless of diluent type (with or without HA), had increased cleavage rates compared to the control (untreated) donors. Other studies have also reported increased blastocyst production rates in Bos taurus beef [35,43] and dairy cattle [19] after superstimulation with $\mathrm{pFSH}$. Although considerable variation has been reported, an increased oocyte developmental competence (cleavage and/or blastocyst rate) was apparent in all studies, reinforcing the beneficial effects of the superstimulation treatment during OPU-IVP programs.

Although different gene expression and a possible decrease in the quality of embryos produced after ovarian stimulation has been reported in mice [67], humans [68], and cattle [69], the present study indicates that pregnancy rates after the transfer of fresh in vitro-produced embryos are likely to be similar, regardless of donor treatment. However, future studies with larger numbers of embryos and recipients are required to confirm these results.

Finally, a greater efficiency of OPU-IVP was obtained in donors treated with a single injection of $200 \mathrm{mg}$ of $\mathrm{pFSH}$ in $0.5 \% \mathrm{HA}$ as compared to those treated with $300 \mathrm{mg}$ of $\mathrm{pFSH}$ in $0.5 \% \mathrm{HA}$. As reported previously [37], the larger dose of $\mathrm{pFSH}$ resulted in an increased follicular diameter but no increase in the number of visible follicles. As expected, a greater proportion of large-sized follicles also resulted in reduced COC recovery rates and consequently, fewer COCs retrieved and cultured and reduced blastocyst production per OPU. Furthermore, the higher pFSH dosage seems to result in more rapid growth rates which may result in altered gene expression in granulosa cells [70] and compromise the efficiency of OPU-IVP. Therefore, to optimize OPU-IVP, improved approaches must be designed to more closely refine the pFSH dosage used as a single injection with HA in potential donors.

In conclusion, the administration of a single dose of pFSH in $0.5 \%$ HA provided a comparable plasma FSH concentration (as measured by AUC of FSH) to the twice-daily pFSH treatment. Regardless of diluent type and administration schedule, superstimulation with pFSH enhanced the overall efficiency of the IVP program in nonlactating Holstein cows. The pFSH diluted in HA appears to be an alternative to extend plasma FSH concentrations, maintaining the beneficial effects of the superstimulation treatment with a simplified protocol and reduced labor. Under the conditions of the current trial, $200 \mathrm{mg}$ of $\mathrm{pFSH}$ seems to be a more appropriate dosage than $300 \mathrm{mg}$ when combined with HA in OPU-IVP programs of nonlactating Holstein donors. Last, pregnancy establishment with in vitro-produced embryos was similar, regardless of the donor treatment before OPU.

\section{Acknowledgments}

The authors would like to thank the Institute of Animal Science (state research farm, Nova Odessa, SP), Agrindus S/A 
(Descalvado, SP), and São José (Tapiratiba, SP) Farms for kindly providing animals and their facilities for this study. They are also thankful to Felipe Pereira Vianna, on behalf of Tecnopec/Agener União Saúde Animal, and CNPq (Conselho Nacional de Desenvolvimento Científico e Tecnológico 140459/2013-8), for supporting this research.

\section{References}

[1] Leroy JL, Van Soom A, Opsomer G, Goovaerts IG, Bols PE. Reduced fertility in high-yielding dairy cows: are the oocyte and embryo in danger? Part II. Mechanisms linking nutrition and reduced oocyte and embryo quality in high-yielding dairy cows. Reprod Domest Anim 2008;43:623-32.

[2] Leroy JL, Rizos D, Sturmey R, Bossaert P, Gutierrez-Adan A, Van Hoeck V, et al. Intrafollicular conditions as a major link between maternal metabolism and oocyte quality: a focus on dairy cow fertility. Reprod Fertil Dev 2012;24:1.

[3] Sartori R, Bastos MR, Wiltbank MC. Factors affecting fertilisation and early embryo quality in single- and superovulated dairy cattle. Reprod Fertil Dev 2010;22:151-8.

[4] Baruselli PS, Sá Filho MF, Ferreira RM, Sales JNS, Gimenes LU, Vieira LM, et al. Manipulation of follicle development to ensure optimal oocyte quality and conception rates in cattle. Reprod Domest Anim 2012;47:134-41.

[5] Ferreira RM, Ayres H, Chiaratti MR, Ferraz ML, Araújo AB, Rodrigues CA, et al. The low fertility of repeat-breeder cows during summer heat stress is related to a low oocyte competence to develop into blastocysts. J Dairy Sci 2011;94:2383-92.

[6] Ratto MH, Peralta OA, Mogollon G, Strobel P, Correa J. Transvaginal ultrasound-guided cumulus oocyte complexes aspiration and in vitro embryo production in suckled beef and lactating dairy cattle on pasture-based management conditions. Anim Reprod Sci 2011; 129:1-6.

[7] Batista EOS, Macedo GG, Sala RV, Ortolan M, Sá Filho MF, Del Valle TA, et al. Plasma AntiMullerian hormone as a predictor of ovarian antral follicular population in Bos indicus (Nelore) and Bos taurus (Holstein) heifers. Reprod Domest Anim 2014;49:448-52.

[8] Pontes JHF, Nonato-Junior I, Sanches BV, Ereno-Junior JC, Uvo S, Barreiros TRR, et al. Comparison of embryo yield and pregnancy rate between in vivo and in vitro methods in the same Nelore (Bos indicus) donor cows. Theriogenology 2009;71:690-7.

[9] Merton JS, de Roos AP, Mullaart E, de Ruigh L, Kaal L, Vos PL, et al Factors affecting oocyte quality and quantity in commercial application of embryo technologies in the cattle breeding industry. Theriogenology 2003;59:651-74.

[10] Silva-Santos KC, Santos GMG, Koetz Júnior C, Morotti F, Siloto LS, Marcantonio TN, et al. Antral follicle populations and embryo production-in vitro and in vivo-of Bos indicus-taurus donors from weaning to yearling ages. Reprod Domest Anim 2014;49 228-32.

[11] Ireland JLH, Scheetz D, Jimenez-Krassel F, Themmen APN, Ward F, Lonergan P, et al. Antral follicle count reliably predicts number of morphologically healthy oocytes and follicles in ovaries of young adult cattle. Biol Reprod 2008;79:1219-25.

[12] Burns DS. Numbers of antral follicles during follicular waves in cattle: evidence for high variation among animals, very high repeatability in individuals, and an inverse association with serum folliclestimulating hormone concentrations. Biol Reprod 2005;73:54-62.

[13] Ireland J, Ward F, Jimenez-Krassel F, Ireland JLH, Smith GW Lonergan $\mathrm{P}$, et al. Follicle numbers are highly repeatable within individual animals but are inversely correlated with FSH concentrations and the proportion of good-quality embryos after ovarian stimulation in cattle. Hum Reprod 2007:22:1687-95.

[14] Silva-Santos KC, Siloto LS, Santos GMG, Morotti F, Marcantonio TN, Seneda MM. Comparison of antral and preantral ovarian follicle populations between Bos indicus and Bos indicus-taurus cows with high or low antral follicles counts. Reprod Domest Anim 2014;49: $48-51$.

[15] Guerreiro BM, Batista EO, Vieira LM, Sá Filho MF, Rodrigues CA, Castro Netto A, et al. Plasma anti-Mullerian hormone: an endocrine marker for in vitro embryo production from Bos taurus and Bos indicus donors. Domest Anim Endocrinol 2014;49:96-104.

[16] Monniaux D, Baril G, Laine AL, Jarrier P, Poulin N, Cognié J, et al. Anti-Müllerian hormone as a predictive endocrine marker for embryo production in the goat. Reproduction 2011;142:845-54.
[17] Rico C, Fabre S, Médigue C, di Clemente N, Clément F, Bontoux M, et al. Anti-müllerian hormone is an endocrine marker of ovarian gonadotropin-responsive follicles and can help to predict superovulatory responses in the cow. Biol Reprod 2009:80:50-9.

[18] Baldrighi JM, Sá Filho MF, Batista EO, Lopes R, Visintin JA, Baruselli PS, et al. Anti-Mullerian hormone concentration and antral ovarian follicle population in Murrah heifers compared to Holstein and Gyr kept under the same management. Reprod Domest Anim 2014;49:1015-20.

[19] Vieira LM, Rodrigues CA, Castro Netto A, Guerreiro BM, Silveira CRA, Moreira RJC, et al. Superstimulation prior to the ovum pick-up to improve in vitro embryo production in lactating and non-lactating Holstein cows. Theriogenology 2014;82:318-24.

[20] Goodhand KL, Watt RG, Staines ME, Hutchinson JSM, Broadbent P]. In vivo oocyte recovery and in vitro embryo production from bovine donors aspirated at different frequencies or following FSH treatment. Theriogenology 1999:51:951-61.

[21] Sendag S, Cetin Y, Alan M, Hadeler KG, Niemann H. Effects of eCG and FSH on ovarian response, recovery rate and number and quality of oocytes obtained by ovum pick-up in Holstein cows. Anim Reprod Sci 2008;106:208-14.

[22] Blondin P, Sirard MA. Oocyte and follicular morphology as determining characteristics for developmental competence in bovine oocytes. Mol Reprod Dev 1995;41:54-62.

[23] Hagemann LJ, Beaumont SE, Berg M, Donnison MJ, Ledgard A Peterson AJ, et al. Development during single IVP of bovine oocytes from dissected follicles: interactive effects of estrous cycle stage, follicle size and atresia. Mol Reprod Dev 1999;53:451-8.

[24] Fair T, Hyttel P, Greve T. Bovine oocyte diameter in relation to maturational competence and transcriptional activity. Mol Reprod Dev 1995;42:437-42.

[25] Hendriksen PJ, Steenweg WN, Harkema JC, Merton JS, Bevers MM, Vos PL, et al. Effect of different stages of the follicular wave on in vitro developmental competence of bovine oocytes. Theriogenology 2004;61:909-20.

[26] Pavlok A, Lucas-Hahn A, Niemann H. Fertilization and developmental competence of bovine oocytes derived from different categories of antral follicles. Mol Reprod Dev 1992;31:63-7.

[27] Arlotto T, Schwartz JL, First NL, Leibfried-Rutledge ML. Aspects of follicle and oocyte stage that affect in vitro maturation and development of bovine oocytes. Theriogenology 1996;45:943-56.

[28] Lonergan P, Monaghan P, Rizos D, Boland MP, Gordon I. Effect of follicle size on bovine oocyte quality and developmental competence following maturation, fertilization, and culture in vitro. Mol Reprod Dev 1994;37:48-53.

[29] Caixeta ES, Ripamonte P, Franco MM, Junior JB, Dode MAN. Effect of follicle size on mRNA expression in cumulus cells and oocytes of Bos indicus: an approach to identify marker genes for developmental competence. Reprod Fertil Dev 2009;21:655-64.

[30] Sirard MA. Follicle environment and quality of in vitro matured oocytes. J Assist Reprod Genet 2011:28:483-8.

[31] Sirard MA. Factors affecting oocyte and embryo transcriptomes. Reprod Domest Anim 2012;47:148-55.

[32] Sirard MA, Richard F, Blondin P, Robert C. Contribution of the oocyte to embryo quality. Theriogenology 2006;65:126-36.

[33] Brevini-Gandolfi TA, Gandolfi F. The maternal legacy to the embryo: cytoplasmic components and their effects on early development. Theriogenology 2001;55:1255-76.

[34] Dieleman SJ, Hendriksen PJM, Viuff D, Thomsen PD, Hyttel P, Knijn HM, et al. Effects of in vivo prematuration and in vivo final maturation on developmental capacity and quality of preimplantation embryos. Theriogenology 2002;57:5-20.

[35] De Roover R, Feugang JMN, Bols PEJ, Genicot G, Hanzen C. Effects of ovum pick-up frequency and FSH stimulation: a retrospective study on seven years of beef cattle in vitro embryo production. Reprod Domest Anim 2008;43:239-45.

[36] Mapletoft RJ, Bó GA. The evolution of improved and simplified superovulation protocols in cattle. Reprod Fertil Dev 2012;24:278.

[37] Roover RD, Genicot G, Leonard S, Bols P, Dessy F. Ovum pick up and in vitro embryo production in cows superstimulated with an individually adapted superstimulation protocol. Anim Reprod Sci 2005; $86: 13-25$.

[38] Malhi PS, Adams GP, Mapletoft RJ, Singh J. Superovulatory response in a bovine model of reproductive aging. Anim Reprod Sci 2008 109:100-9.

[39] Demoustier MM, Beckers JF, Van Der Zwalmen P, Closset J, Gillard JL, Ectors F. Determination of porcine plasma follitropin levels during superovulation treatment in cows. Theriogenology 1988;30:379-86. 
[40] Laster DB. Disappearance and uptake of [125I]FSH in the rat, rabbit, ewe and cow. J Reprod Fertil 1972;30:407-15.

[41] Tríbulo A, Rogan D, Tribulo H, Tribulo R, Alasino RV, Beltramo D, et al. Superstimulation of ovarian follicular development in beef cattle with a single intramuscular injection of Folltropin-V. Anim Reprod Sci 2011;129:7-13.

[42] Tríbulo A, Rogan D, Tríbulo H, Tríbulo R, Mapletoft RJ, Bó GA. Superovulation of beef cattle with a split-single intramuscular administration of Folltropin-V in two concentrations of hyaluronan. Theriogenology 2012;77:1679-85.

[43] Blondin P, Bousquet D, Twagiramungu H, Barnes F, Sirard MA. Manipulation of follicular development to produce developmentally competent bovine oocytes. Biol Reprod 2002;66:38-43.

[44] Ongaratto FL, Tribulo A, Ramos M, Rodriguez P, Bo GA. Oocyte recovery rates and in vitro blastocyst production in cattle treated with a single injection of folltropin-v diluted in a slow-release formulation. Reprod Fertil Dev 2011;23:202-3.

[45] NRC. Nutrient requirements of dairy cattle. Washington, DC. Paperback; 2001.

[46] Ayres H, Ferreira RM, Torres-Júnior JRS, Demétrio CGB, de Lima CG, Baruselli PS. Validation of body condition score as a predictor of subcutaneous fat in Nelore (Bos indicus) cows. Livest Sci 2009;123: 175-9.

[47] Mapletoft RJ, Bó GA, Baruselli PS. Control of ovarian function for assisted reproductive technologies in cattle. Anim Reprod 2009;6: 114-24.

[48] Bó GA, Baruselli PS, Moreno D, Cutaia L, Caccia M, Tríbulo R, et al. The control of follicular wave development for self-appointed embryo transfer programs in cattle. Theriogenology 2002;57:53-72.

[49] Bolt DJ, Rollins R. Development and application of a radioimmunoassay for bovine follicle-stimulating hormone. J Anim Sci 1983; 56:146-54.

[50] Bols PEJ, Van Soom A, Ysebaert MT, Vandenheede JMM, de Kruif A. Effects of aspiration vacuum and needle diameter on cumulus oocyte complex morphology and developmental capacity of bovine oocytes. Theriogenology 1996;45:1001-14.

[51] Seneda MM, Esper CR, Garcia JM, Oliveira JA, Vantini R. Relationship between follicle size and ultrasound-guided transvaginal oocyte recovery. Anim Reprod Sci 2001;67:37-43.

[52] Bavister BD, Yanagimachi R. The effects of sperm extracts and energy sources on the motility and acrosome reaction of hamster spermatozoa in vitro. Biol Reprod 1977;16:228-37.

[53] Watanabe YF, Watanabe MR, Galerani MAV, Vila RA, Lôbo RB. The influence of B2 and modified CR2 on the in vitro production of bovine with cumulus and oviduct co-culture. Theriogenology 1999; $51: 259$.

[54] Rodrigues CA, Teixeira AA, Ferreira RM, Ayres H, Mancilha RF, Souza $\mathrm{AH}$, et al. Effect of fixed-time embryo transfer on reproductive efficiency in high-producing repeat-breeder Holstein cows. Anim Reprod Sci 2010;118:110-7.

[55] Hiraizumi S, Nishinomiya H, Oikawa T, Sakagami N, Sano F, Nishino O, et al. Superovulatory response in Japanese Black cows receiving a single subcutaneous porcine follicle-stimulating hormone treatment or six intramuscular treatments over three days. Theriogenology 2015;83:466-73.

[56] Bo GA, Hockley DK, Nasser LF, Mapletoft RJ. Superovulatory response to a single subcutaneous injection of Folltropin-V in beef cattle. Theriogenology 1994;42:963-75.

[57] Kelly P, Duffy P, Roche JF, Boland MP. Superovulation in cattle: effect of FSH type and method of administration on follicular growth, ovulatory response and endocrine patterns. Anim Reprod Sci 1997;46:1-14.

[58] Chasombat J, Sakhong D, Nagai T, Parnpai R, Vongpralub T. Superstimulation of follicular growth in Thai native heifers by a single administration of follicle stimulating hormone dissolved in polyvinylpyrrolidone. J Reprod Dev 2013;59:214-8.

[59] Hashimoto S, Kimura K, Kuramochi T, Aoyagi K, Hirako M, Kawaguchi M, et al. Responsiveness of rabbits to superovulation treatment by a single injection of follicle-stimulating hormone with aluminum hydroxide gel. Mol Reprod Dev 2007;74:1208-12.

[60] Aller JF, Mucci NC, Kaiser GG, Ríos G, Callejas SS, Alberio RH. Transvaginal follicular aspiration and embryo development in superstimulated early postpartum beef cows and subsequent fertility after artificial insemination. Anim Reprod Sci 2010;119:1-8.

[61] Nivet AL, Bunel A, Labrecque R, Belanger J, Vigneault C, Blondin P, et al. FSH withdrawal improves developmental competence of oocytes in the bovine model. Reproduction 2012;143:165-71.

[62] Krisher RL. What is oocyte quality? AETA/CETA-ACTE Annual Meetings. Wisconsin 2014. p. 57-74.

[63] Labrecque R, Sirard MA. The study of mammalian oocyte competence by transcriptome analysis: progress and challenges. Mol Hum Reprod 2013;20:103-16.

[64] Mourot M, Dufort I, Gravel C, Algriany O, Dieleman S, Sirard MA. The influence of follicle size, FSH-enriched maturation medium, and early cleavage on bovine oocyte maternal mRNA levels. Mol Reprod Dev 2006;73:1367-79.

[65] Chu T, Dufort I, Sirard MA. Effect of ovarian stimulation on oocyte gene expression in cattle. Theriogenology 2012;77:1928-38.

[66] Dias FCF, Khan MIR, Sirard MA, Adams GP, Singh J. Differential gene expression of granulosa cells after ovarian superstimulation in beef cattle. Reproduction 2013;146:181-91.

[67] Fauque P, Jouannet P, Lesaffre C, Ripoche MA, Dandolo L, Vaiman D, et al. Assisted reproductive technology affects developmental kinetics, H19 imprinting control region methylation and $\mathrm{H} 19$ gene expression in individual mouse embryos. BMC Dev Biol 2007;7:116.

[68] Sato A, Otsu E, Negishi H, Utsunomiya T, Arima T. Aberrant DNA methylation of imprinted loci in superovulated oocytes. Hum Reprod 2007;22:26-35.

[69] Mundim TC, Ramos AF, Sartori R, Dode MA, Melo EO, Gomes LF, et al. Changes in gene expression profiles of bovine embryos produced in vitro, by natural ovulation, or hormonal superstimulation. Genet Mol Res 2009;24:1398-407.

[70] García Guerra A, Tribulo A, Yapura J, Adams GP, Singh J, Mapletoft RJ. Lengthened superstimulatory treatment in cows: evidence for rescue of follicles within a wave rather than continuous recruitment of new follicles. Theriogenology 2015;84: 467-76. 